\title{
PENGARUH METODE PEMBELAJARAN COOPERATIVE TERHADAP HASIL BELAJAR INSTALASI BANGUNAN SEDERHANA KELAS X TITL SMKN 34 JAKARTA \\ ${ }^{1}$ Achmad Abi Rafdi, ${ }^{2}$ Faried Wadjdi, ${ }^{3}$ Massus Subekti \\ ${ }^{1,2,3}$ PendidikanTeknik Elektro, Fakultas Teknik, Universitas Negeri Jakarta \\ Email : abirafdii.ar@gmail.com
}

\begin{abstract}
The purpose of this study is to determine the effect of cooperative learning methods and learning motivation on results. Learning Simple Building Installation. The population in this study were all students of Class X TITL SMK 32, totaling 64 students. In this study using expost facto method with quantitative approach. Research data is in the form of posttest results of class X students. Data analysis techniques used normality test, namely the liliefors test with a significant level of 0.05 indicating that the data were normally distributed while the homogeneity test using the fisher test showed that the data was homogeneous. The results showed that the fcount value was greater than ftabel with a significant level of 0.05, namely $56.761<2.5$ (Method) so that the first hypothesis which states that there are differences in learning outcomes using the STAD method and the Snowball Throwing Method. The second hypothesis states that there are significant differences between learning outcomes in the upper class and those in the lower class. (Calculate> Ftable; 9,549> 2,5). The third hypothesis states that there are differences in learning outcomes between learning methods and grade level (Fcount <Ftable; $33.02<2.5)$. The results of the study conclude that there are significant differences between learning methods and class levels.

Keywords: cooperative, learning methods, the results of the Study, the influence of learning methods
\end{abstract}

\begin{abstract}
Abstrak
Tujuan dari penelitian ini adalah untuk mengetahui Pengaruh Metode Belajar Kooperatif dan Motivasi Belajar Terhadap Hasil Belajar Instalasi Bangunan Sederhana. Populasi pada penelitian ini adalah seluruh siswa Kelas X TITL SMKN 32 yang berjumlah 64 orang siswa. Pada penelitian ini menggunakan metode expost facto dengan pendekatan kuantitatif. Data penelitian berupa hasil posttest siswa kelas X. Teknik analisis data menggukan uji normalitas yaitu uji liliefors dengan taraf signifikan 0,05 menunjukan bahwa data berdistribusi normal sedangkan uji homogenitas menggunakan uji fisher menunjukan bahwa data bersifat homogen. Hasil penelitian menunjukan bahwa nilai fhitung lebih besar dari ftabel dengan taraf signifikan 0,05 yaitu $56.761<2,5$ (Metode) sehingga hipotesis pertama yang menyatakan bahwa adanya perbedaan hasil belajar menggunakan metode STAD dan Metode Snowball Throwing. Hipotesis yang kedua yang menyatakan terdapat perbedaan yang signifikan antara hasil belajar yang berada di kelas atas dengan sis yang berada di kelas bawah. (Fhitung > Ftabel; $9.549>2,5$ ). Hipotesis ke tiga yang menyatakan bahwa adanya perbedaan hasil belajar antara metode pembelajaran dengan tingkat kelas (Fhitung < Ftabel; 33.02 $<2,5)$. Hasil penelitian menyimpulkan bahwa antara metode pembelajaran dengan tingkat kelas terdapat perbedaan yang signifikan.
\end{abstract}

Kata Kunci : cooperative, metode pembelajaran, Hasil Belajar, Pengaruh metode pembelajaran

\section{PENDAHULUAN}

Menurut Joyce dan Well dalam Mulyani Sumantri, (1991:42) metode pembelajaran adalah kerangka konseptual yang melukiskan prosedur yang sistematis dalam mengorganisasikan pengalaman belajar untuk mencapai tujuan pembelajaran tertentu, dan memiliki fungsi sebagai pedoman bagi para perancang pembelajaran dan para pengajar dalam merencanakan dan melaksanakan aktifitas belajar mengajar. Metode pembelajaran sangat banyak sekali, dari mulai yang sederhana sampai metode kekinian sesuai dengan kurikulum 2013. Walaupun kurikulum 2013 telah disahkan namun dibeberapa sekolah masih menggunakan metode pembelajaran yang berpusat pada guru yaitu metode ceramah. Metode pembelajaran ceramah adalah metode pembelajaran dimana pengajar memberikan materi satu arah. Dalam metode ceramah, siswa masih bersifat pasif yaitu hanya mendengarkan penjelasan dari guru, sehingga terlihat guru lebih aktif dari 
pada siswa. Metode ceramah, siswa disini hanya lebih sering mendengarkan guru menyampaikan materi dan jarang sekali terlibat aktif dalam kegiatan belajar terutama saat memberikan materi berupa teori.

Dalam metode Ceramah pengajar memberikan penyampaian satu arah menyebabkan kurangnya peran aktif siswa yang hanya mendengar saat kegiatan belajar mengajar berlangsung. Untuk meningkatkan keaktifan siswa, maka dibutuhkan metode pembelajaran yang relavan guna meningkatkan keaktifan siswa sehingga dapat mencapai hasil belajar yang maksimal salah satunya dengan menggunakan metode belajar kelompok atau metode belajar cooperative.

Metode belajar kelompok merupakan salah satu metode yang berupaya menumbuhkan motivasi siswa lewat peran aktif siswa dikelas dengan membuat kelompok kecil yang bersifat beragam mulai dari ras, etnis, agama, jenis kelamin, dan prestasi belajarnya. Penggunaan kelompok belajar dapat mendorong siswa yang pasif atau malu bertanya akan aktif bertanya pada teman sejawatnya dan dapat dibantu oleh teman sekelompoknya untuk memahami konsep atau materi pelajaran yang disampaikan oleh pengajar. Dalam belajar kelompok, akan terjadi interaksi antara siswa yang kemampuan tinggi dengan siswa kemampuan rendah tentang materi yang dianggap sulit, dalam pembelajaran kelompok siswa yang malu dan malas bertanya akan bertanya dengan teman sekelompoknya tentang materi yang di sulit dipahami. Siswa yang pandai akan mengajarkan temannya yang kurang paham atau selalu melibatkannya dalam kegiatan belajar. Guru di sini berperan sebagai fasilitator.

Pembelajaran kelompok akan membuat pembelajaran menjadi menyenangkan yang dimana akan meningkatkan motivasi belajar bagi siswa yang dimana akan meningkatkan hasil belajar, karena pembelajaran yang lebih menyenangkan dan siswa yang pasif termotivasi untuk ikut dalam bekerja kelompok dan berdiskusi karena melihat teman sekelompoknya berperan aktif dalam diskusi dan pembelajaran. Lalu saat belajar kelompok dan diskusi berlangsung pun akan muncul motivasi belajar karena ada dorongan dan ajakan dari teman sekolompoknya yang aktif kepada temannya yang kurang aktif untuk ikut berperan aktif dalam kegiatan belajar kelompok atau diskusi. Sehubungan dengan meningkatnya motivasi siswa dari segi interistik dan eksteristik maka akan berpengaruh terhadap hasil belajar siswa yang dikarenakan memiliki motivasi belajar dan juga keaktifan yang meningkat. Pembelajaran kelompok ini akan menggunakan dua metode pertama, metode cooperative tipe STAD merupakan pembelajaran cooperative atau berkelompok yang lebih menekankan ke pemahaman konsep dan pencapaian kemajuan hasil belajar. STAD (Student Teams Achievement Division) menggunakan kuis - kuis yang bersifat individual disetiap akhir pembelajaran yang bertujuan mengetahui seberapa paham peserta didik atau siswa menguasai materi yang telah disampaikan dan didiskusikan dengan kelompok masing - masing. Metode kedua, metode cooperative learning Snowball Throwing yang dimana sama seperti STAD membuat kelompok yang bersifat heterogen namun disini peserta didik akan diberi sebuah materi oleh guru dan guru akan menyampaikan materi ke setiap ketua kelompok dimana nanti ketua kelompok akan menjelaskan ke teman sekolompoknya dan setiap peserta didik akan membuat bola kertas yang berisi satu pertanyaan yang nantinya akan diberikan ke peserta didik kelompok lain. Kedua metode yang digunakan pada kelas yang berbeda, dan akan dilihat hasil belajar dari masing - masing individu dalam kelompok setelah diterapkan kedua metode ini. Berdasarkan penjelasan diatas, maka peneliti akan meneliti kedua variabel tersebut terhadap hasil belajar instalasi bangunan sederhana kelas $X$ TITL di SMKN 34 Jakarta. 


\section{METODE}

Pada penelitian ini menggunakan metode penelitian ex post facto dengan pendekatan kuantitatif. Penelitian ex post facto yaitu penelitian yang hanya mengungkapkan fakta berdasarkan pengukuran gejala yang telah terjadi pada diri responden (Nana Sudjana dan Ibrahim, 2007: 56). Pada penelitian ini tidak dilakukan manipulasi terhadap variabel penelitian. Pengukuran dilakukan secara alami tanpa perlakuan khusus.

Metode penelitian eksperimen yang digunakan adalah Pretest and Posttest Control Design dengan pengambilan sampel untuk kelas eksperimen dan kelas kontrol dengan teknik Simple Random Sampling dan pembagian kelas menggunakan rumus 50\%:50\%. Hasil belajar yang akan didapat berasal dari data kelas eksperimen dan dari kelas kontrol

\section{HASIL DAN PEMBAHASAN}

Hasil hipotesis pertama bahwa $F_{\text {hitung }} 56.761>F_{\text {tabel }} 2.5$, maka dapat dinyatakan hipotesis ditolak. Dengan demikian secara perhitungan dapat dikatakan terdapat perbedaan yang signifikan pengaruh menggunakan metode belajar koperatif learning tipe STAD dengan yang menggunakan metode koperatif learning tipe snowball. Dengan kata lain faktor metode koperatif learning tipe STAD berpengaruh terhadap hasil belajar siswa kelas X SMKN 34 Jakarta.

Hipotesis yang kedua yang menyatakan bahwa $F_{\text {hitung }}>F_{\text {tabel }}$, maka dapat dinyatakan hipotesis ditolak. Dengan demikian dapat dilihat dari hasil perhitungan bahwa terdapat terdapat perbedaan hasil belajar siswa yang berada di kelas atas dengan siswa yang berada di kelas bawah pada siswa kelas X TITL di SMKN 34 Jakarta.

Hipotesis ke tiga yang menyatakan bahwa $F_{\text {hitung }}>F_{\text {tabel }}$, maka hipotesis ditolak. Dengan demikian dapat dilihat dari hasil perhitungan bahwa adanya perbedaan antara metode pembelajaran dengan tingkat kelas secara bersama - sama dengan hasil belajar siswa kelas X TITL di SMKN 34 Jakarta.

Tabel 1. Rangkuman Pengujian Hipotesis

\begin{tabular}{lccc}
\hline \multicolumn{1}{c}{ Data } & Fhitung & Ftabel & Keterangan \\
\hline $\begin{array}{l}\text { Metode } \\
\begin{array}{l}\text { Pembelajaran } \\
\text { Cooperative }\end{array}\end{array}$ & 56.761 & 2,5 & Ho ditolak, \\
$\begin{array}{l}\text { Tingkatan kelas } \\
\text { 9.549 }\end{array}$ & 2,5 & Ho ditolak, \\
$\begin{array}{l}\text { Metode } \\
\text { pembelajaran } \\
\begin{array}{l}\text { Cooperative dan } \\
\text { tingkatan kelas }\end{array}\end{array}$ & 2.5 & Ho ditolak, \\
\end{tabular}

\section{KESIMPULAN DAN SARAN Kesimpulan}

1. Hasil hipotesis pertama bahwa $F_{\text {hitung }}>$ $F_{\text {tabel }}$ maka dapat dinyatakan Ho ditolak dan Hi diterima. Dengan demikian secara perhitungan dapat dikatakan terdapat perbedaan yang signifikan pengaruh menggunakan metode belajar koperatif learning tipe STAD dengan yang menggunakan metode koperatif learning tipe snowball. Dengan kata lain faktor metode koperatif learning tipe STAD berpengaruh terhadap hasil belajar siswa kelas X SMKN 34 Jakarta.

2. Hipotesis yang kedua yang menyatakan bahwa $F_{\text {hitung }}>F_{\text {tabel }}$, maka dapat dinyatakan Ho ditolak dan Hi diterima. Dengan demikian dapat dilihat dari hasil perhitungan bahwa terdapat terdapat perbedaan hasil belajar praktik siswa yang berada di kelas atas dengan siswa yang berada di kelas bawah pada siswa kelas X TITL di SMKN 34 Jakarta

3. Hipotesis ke tiga yang menyatakan bahwa $F_{\text {hitung }}>F_{\text {tabel }}$, maka dapat dinyatakan Ho ditolak dan Hi diterima. Dengan demikian dapat dilihat dari hasil perhitungan bahwa adanya perbedaan antara metode pembelajaran dengan tingkat kelas secara bersama - sama dengan hasil siswa pada kelas X TITL di SMKN 34 Jakarta.

\section{Saran}

1. Guru disarankan agar dalam proses kegiatan belajar menggunakan metode 
cooperative karena dengan menggunakan metode ini siswa cenderung lebih aktif ikut serta dalam kegiatan belajar dan juga guru harus memberikan motivasi untuk siswa agar semangat dan meningkatnya keinginan siswa untuk belajar disekolah maupun dirumah.

2. Untuk SMK disarankan agar memberikan pelatihan mengenai metode pembelajaran yang inovatif kepada guru. Agar dalam pemilihan metode pembelajaran dapat memaksimalkan proses pembelajaran.

\section{DAFTAR PUSTAKA}

Anitah, Sri., 2008. Strategi Pembelajaran di SD, Jakarta: Universitas Terbuka.

Arief, Armai. 2002. Pengantar Ilmu dan Metodologi Pendidikan Islam. Jakarta: Penerbit Ciputat Pers.

Badan Standarisasi Nasional. 2000. Persyaratan Umum Instalasi Listrik 2000 (PUIL 2000), Jakarta: BSN.

Dali Santun Naga. 2008. Probabilitas dan Sekor Pada Hipotesis Statistika. Jakarta: UPT Universitas Tarumanegara

Darmadi, Hamid. 2010. Pengantar Pendidikan Kewarganegaraan. Jakarta: Rineka Cipta.

Djamarah Syaiful Bahri. 2011. Psikologi Belajar, Jakarta : Rineka Cipta.

Dimyati dan Mudjiono. 2002. Belajar Dan Pembelajaran.Jakarta: PT Rineka Cipta.

Dr. M. Sobry Sutikno, 2009. Belajar dan Pembelajaran. Prospect. Bandung.

Gerlach dan Ely 1971. Teaching \& Media: A Systematic Approach. Second Edition, by V.S. Gerlach \& D.P. Ely, 1980, Boston, MA: Allyn and Bacon. Copyright 1980 by Pearson Education

Handoko, Priyo 2000. Pemasangan Instalasi Listrik Dasar. Kanisius.

Hidayat, Kosadi. 1990. Strategi Belajar Mengajar. Bandung.

Joyce, Bruce \& Marsha Weil. 1992. Models of Teachinf. USA: Allyn and Bacon.

Lie, A. 2004. Cooperative Learning. Jakarta:Gramedia.
2008. Penelitian

Tindakan Kelas. Jakarta: Bumi Aksara .

Mohamad Nur. 2008. Pembelajaran Kooperatif. Surabaya: Pusat Sains dan Matematika Sekolah UNESA.

Mulyasa, Muryadi, Guru Profesiona, Rosdakarya, Bandung, 2008.

Nana Sudjana. 2005, Penelitian Hasil Proses Belajar Mengajar, Bandung: PT. Remaja Rosidakarya.

Nana Sudjana. 2009. Penilaian Hasil Proses Belajar Mengajar. Bandung: PT Remaja Rosdakarya

Ruslan, Rosady. 2003. Metode Penelitian PR dan Komunikasi. Jakarta : PT. Raja Grafindo Persada.

Sardiman. 2003. cooperative learning. Grasindo. Jakarta

Slameto. 2003. Belajar dan Faktor-Faktor yang Mempengaruhinya. Jakarta: Penerbit Rineka Cipta.

Slavin,R.E. 2008. Cooperative Learning Teori, Riset dan Praktik. Bandung: Nusa Media

Suryabrata Sumadi, Psikologi Pendidikan, (Jakarta : Rajawali, 1984)

Takeshi Sato \& N. Sugiarto. 1986. Menggambar Mesin Menurut Standar ISO. Pradnya Paramita. Jakarta.

Trianto, 2010, Mengembangkan Model Pembelajaran Tematik, Jakarta: PT Prestasi Pustaka.

Widyantini. 2008. Penerapan Pendekatan Kooperatif STAD Dalam Pembelajaran Matematika SMP. Yogyakarta : Departemen Pendidikan Nasional. 